\title{
Benchmarking Malaysian youth work practitioner ethics
}

\begin{abstract}
Ethics are a core component of professionalism in youth work yet little research has been done in this area. Given the growing demand for greater standards and quality of youth work, there is an urgent need for research in work ethics among contemporary youth development workers in the country. The current self-administered survey was designed to investigate selfperception in the areas of work ethics among 601 government and non-government youth workers. The survey showed that the samples fared well in terms of ethics as defined by respect for others, responsibility and honesty, with respect for others more pronounced than the other two. Age and years of involvement in youth work correlated positively and significantly with respect for others and responsibility. Job sector correlated negatively and significantly with honesty, and academic qualification correlated negatively and significantly with responsibility. Recommendations for work ethics training and development are discussed.
\end{abstract}

Keyword: Ethics, youth work 